\title{
Homogenous and heterogeneous combustion in the secondary chamber of a straw-fired batch boiler
}

\author{
Mateusz Szubel ${ }^{1, *}$, Wojciech Adamczyk ${ }^{2}$, Grzegorz Basista ${ }^{1}$, Mariusz Filipowicz ${ }^{1}$ \\ ${ }^{1}$ AGH University of Science and Technology, Faculty of Energy and Fuels, al. Mickiewicza 30, 30-059 Krakow, Poland \\ ${ }^{2}$ Silesian University of Technology, Institute of Thermal Technology, Konarskiego 22, 44-100 Gliwice
}

\begin{abstract}
Currently, the attention of the producers of biomass batch boilers is mostly focused on the problem of the total efficiency of energy conversion, $\mathrm{CO}$ emissions as well as particulate matter emissions. Due to the regulations of the European Union, the emissions referred to above have to be kept at certain levels because of health considerations, but also because of the necessity to increase the efficiency of the devices. The paper presents the process of analysis of a straw-fired small-scale boiler. In this study, the early stage CFD model presented in a previous paper [1] has been improved and evaluated. Based on [2], an additional set of specimens participating in homogeneous gas reactions was assumed to describe the combustion process sufficiently. Associated Arrhenius parameters have been applied for the description of these reactions. ANSYS Fluent 16 has been used to perform the analysis and the analysis was focused on the CO emissions level as well as on the impact of the modelling approach on the result of the computing. Moreover, losses related to incomplete combustion have been calculated for each of the considered cases.
\end{abstract}

\section{Biomass combustion - selected aspects of theory and Computational Fluid Dynamics}

Biomass combustion involves many advanced physical and chemical processes. The characteristics of the process depend on the properties of the applied fuel as well as on the technology of combustion [3].

From the point of view of fuel properties, special consideration should be given to the high humidity content and to the volatiles. Due to this fact, four general combustion stages can be listed $[4,5,6]$ : warming and drying, thermal decomposition of the fuel components, combustion of the products of the thermal decomposition and combustion of charcoal.

Biomass combustion involves many advanced physical and chemical processes. Depending on the gasifying agent, the composition of the mixture that is the product of gasification varies. However, the same processes have to be taken into account in each case: $\mathrm{H}_{2}$ - $\mathrm{O}_{2}$ system, oxidation of carbon monoxide as well as conversion of methane. Oxidation of higher hydrocarbons is of lower significance. Moreover, reactions resulting in the creation of nitrogen oxides are also important.

\subsection{Selected mechanisms of combustion in the gaseous phase}

The $\mathrm{H}_{2}-\mathrm{O}_{2}$ system is important in itself, but also as a part of some schematics or stage of the oxidation of hydrocarbons and in some specific cases also CO. A detailed description of hydrogen oxidation is presented in $[7,8]$. The mechanism of $\mathrm{H}_{2}$ oxidation differs depending on temperature, pressure and degree of reaction. When it comes to the modelling of the $\mathrm{H}_{2}-\mathrm{O}_{2}$ system, as much as 40 reactions can be taken into account, including eight compounds, such as $\mathrm{H}_{2}, \mathrm{O}_{2}$, $\mathrm{H}_{2} \mathrm{O}, \mathrm{OH}, \mathrm{O}, \mathrm{H}$ and $\mathrm{H}_{2} \mathrm{O}_{2}$ [8].

The oxidation of carbon monoxide is important as a stage of the combustion of the volatile products of the gasification. It is also an extremely important element of the oxidation of hydrocarbons. A general, simplified description of the oxidation of $\mathrm{CO}$ should include the following stages: the decomposition of the fuel with the release of $\mathrm{CO}$ and the final oxidation of $\mathrm{CO}$ to $\mathrm{CO} 2$ [3].

The process of $\mathrm{CO}$ oxidation is really slow [7, 8], except for reactions in which some compounds of hydrogen are present. Small amounts of $\mathrm{H}_{2} \mathrm{O}$ and $\mathrm{H}_{2}$ have a huge impact on the oxidation rate. The reason for that is the participation of hydroxyl radicals in the oxidation of $\mathrm{CO}$ [9]. When the compound including hydrogen is $\mathrm{H}_{2} \mathrm{O}$, this process can be described in a simplified way using the equations below $[8,10]$ :

$$
\begin{aligned}
& \mathrm{CO}+\mathrm{O}_{2} \rightarrow \mathrm{CO}_{2}+\mathrm{O} \\
& \mathrm{O}+\mathrm{H}_{2} \mathrm{O} \rightarrow \mathrm{OH}+\mathrm{OH} \\
& \mathrm{CO}+\mathrm{OH} \rightarrow \mathrm{CO}_{2}+\mathrm{H} \\
& \mathrm{H}+\mathrm{O}_{2} \rightarrow \mathrm{OH}+\mathrm{O}
\end{aligned}
$$

The reaction described by equation 1 occurs slowly and it is insignificant in the $\mathrm{CO}_{2}$ formation process. Reaction 2 results in the formation of hydroxyl radicals, which have to be provided as a substrate in the next step. Moreover, this stage causes other processes due to the production of hydrogen atoms, which are able to react

*Corresponding author: mszubel@agh.edu.pl 
with $\mathrm{O}_{2}$ (production of $\mathrm{OH}$ groups). Oxygen radicals are an additional product of the described process. Both hydroxyl and oxygen radicals are present in the third stage (described by equation 3 ), which is a key step in the $\mathrm{CO}$ oxidation [8].

The situation is a little different when hydrogen instead of water is the oxidizing factor of $\mathrm{CO}$. The following reactions take place [8]:

$$
\begin{aligned}
& \mathrm{O}+\mathrm{H}_{2} \rightarrow \mathrm{OH}+\mathrm{H} \\
& \mathrm{OH}+\mathrm{H}_{2} \rightarrow \mathrm{H}_{2} \mathrm{O}+\mathrm{H}
\end{aligned}
$$

However, it is necessary to take into account the whole $\mathrm{H} 2-\mathrm{O} 2$ system to describe the full process of oxidation of $\mathrm{CO}$ in the presence of hydrogen.

Methane $\left(\mathrm{CH}_{4}\right)$ is unique in the group of alkanes due to the special tetrahedral molecular structure with $\mathrm{C}-\mathrm{H}$ chemical bonds, which are characterized by high energy. This fact results in some uncommon features, such as relatively high ignition temperature and low flame speed. The kinetics of $\mathrm{CH}_{4}$ combustion are well known and the directions of the process are described by a number of reactions. For example, in [8] the author used 177 reactions to describe the complex mechanism of combustion of $\mathrm{CH} 4$ in a $\mathrm{C}-\mathrm{H}-\mathrm{O}$ system as well as 102 reactions with $\mathrm{N} 2$.

Processes presented above show that even the oxidation of the simple chemical compounds that are taken into consideration is a complicated process. The description of hydrocarbons is encumbered with a lot of problems and limitations. However, it is possible to implement some empirical global models, which include series of simplifications and estimations. Examples of single step and multistep global models as well as values of important kinetic parameters can be found in the literature $[11,12]$.

\subsection{Particulate emissions from biomass combustion in small size biomass boilers}

The environmental impact resulting from the conversion of solid biomass into energy in the combustion process in small-scale installations causes particulate matter (PM) emissions, which becomes a critical aspect if compared to the considerably lower PM emissions from methane boilers [15].

PM can consist of mineral substances as well as organic material. Due to the fact that the content of different components in the biomass varies greatly, the particulate emissions also vary depending on the device technology and the applied fuel.

A few significant factors influencing the PM emissions have to be listed. Apart from the number of problems connected to the construction of the combustion chamber, it is the direct relationship between the PM emissions and the value of the excess air, as well as the improper content of moisture in the fuel. High moisture content has a negative impact on PM emissions. However, straw that is too dry $(<10 \%)$ is not recommended for the same reason.

Considering the heat balance of the boiler, transportation of the solid particles with the exhaust is undesirable due to the content of combustible organic components. The amount of energy related to the material leaving the combustion chamber with the exhaust is called the loss of fly ash. However, while the organic part of the PM causes problems, the inorganic ones are also problematic due to the possible presence of potassium, sulphur, sodium and zinc, which could lead to increased emissions. The greatest amount of PM emissions from biomass combustion consists in particles with an aerodynamic diameter smaller than 2.5 [15].

\subsection{Simplified approach to modelling of combustion and reduced mechanisms of chemical reactions}

The computational cost of chemical kinetics evaluation and the associated species transport equations is something that has to be taken into account when designing a combustion model. Moreover, the costs grow rapidly with the number of applied reactions as well as the level of complexity [8, 13, 14].

To allow for more efficient performance of simulations of advanced combustion problems, simplified processes called reduced mechanisms have been developed. A reduced mechanism of a chemical reaction includes a relatively low number of equations, which is enough to achieve a satisfying agreement of the theoretical description of the reaction and the actual process. A more detailed description of specific reduced mechanisms of combustion can be found in [13].

The simplified approach to the combustion process used in CFD numerical modelling is useful in relatively simple cases, like homogenous premixed combustion, as well as in complicated problems, such as simulations of operation of combustors - both conventional fuel-fired and biomass-fired. Moreover, it is possible to extend the functionality of commercial CFD-solvers in terms of solid phase descriptions and solid-gas interactions by defining key components of the solid phase (so-called pseudocomponents) and developing appropriate equations [2]. Of course, all stages preceding the direct combustion, such as drying and warming, devolatilization and interactions of the products with the solid phase have to be taken into account in the model.

\subsection{Computational Fluid Dynamics as a tool in studies of biomass thermo-chemical conversion}

In the paper by Xue, Heindler and Fox [16], the CFD numerical model has been developed to describe the process of fast biomass pyrolysis in a reactor with a fluidized bed. The authors took into account the many stages of the process by properly defining the kinetics of the reactions. This analysis was focused on the dynamics of heating the fuel, the reactions in the solid phase (including char formation) as well as the spatial distribution of tar and gases in the reactor. Similar studies have been performed by Blondeau and Jeanmart in [17], where an advanced model describing the pyrolysis of fuel particles in a pulverized coal-fired boiler has been proposed. 
Results of numerical simulations as well as data obtained in experimental studies are often used in more advanced numerical analyses, including numerical studies of combustors with a fixed bed. Studies described in [18] are devoted to a subgrid-scale model, which has been developed to analyse the intraparticle gradients, the interactions with other particles and the gas phase. The Euler-Euler CFD framework has been applied. According to the remark in subsection 3.2, to simulate the entire system, the authors of the paper have combined the main model with other submodels describing the gas phase, the bed reaction and the interactions between them.

A slightly different approach has been presented by Buczyński, Weber and Szlęk in [18], where a CFD-based model has been developed for predicting the performance of a central heating boiler fired with solid fuels. A unique feature of this model is that it does not require a priori distinction between the fixed-bed region and the free-board region. The model was used to optimize both the operation algorithm and the design of the heating unit.

The development of the numerical model describing the heterogeneous combustion of biomass based on experimental data and validation of computations allows to perform variant analysis, which can be focused i.a. on parameters such as the impact of the excess air, air staging or the number and direction of the air nozzles on the process of combustion and the heat balance of the boiler. Such works are described in many papers, i.e. [1, 2, 19, 20].

Based on information contained in the literature, it is possible to prepare numerical simulations of low power straw-fired batch boilers. Currently, the application of the CFD codes to study this type of boilers is still under development, but some elaborations describing adequate approaches are already available [2]. The further part of the paper is devoted to the description of an extension of the existing CFD model of a $180 \mathrm{~kW}$ straw-fired batch boiler.

\section{Experimental studies of the post- combustion in the secondary combustion chamber of a $180 \mathrm{~kW}$ biomass boiler}

\subsection{Characteristics of the examined boiler}

The analyses described in this paper were devoted to a solid biomass batch boiler (Ekopal RM40 model). The EKOPAL RM40 boiler (figure 1) is a $180 \mathrm{~kW}$ unit classified in the group of gasification boilers. The dimensions of the primary combustion chamber are: 2405/3075/1880 $\mathrm{mm}$ (height/width/depth). The device is designed to burn straw in the form of cubes or bales.

The combustion of fuel proceeds in two stages: in the primary combustion chamber and the secondary combustion chamber. In the first stage, gasification of the fuel in the primary chamber takes place under controlled air deficiency. Combustible gaseous products of the first stage flow into the secondary chamber, where the post-combustion occurs. The next element behind the secondary combustion chamber and the ash separator is a heat exchanger, consisting of tubes arranged in three rows. The separation of the combustion stages as well as the application of the exhaust heat exchanger causes an increase in the total efficiency of energy conversion (for the nominal conditions of operation approximately 84 $\%$ ).

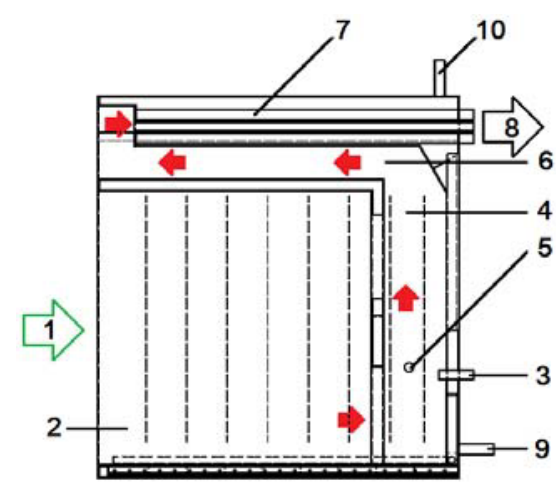

Figure 1. Cross section of the boiler: 1) direction of the fuel loading (door), 2) primary combustion chamber, 3) primary air nozzles connected with the fan through the air manifold, 4) secondary combustion chamber, 5) secondary air nozzle on the side wall of the secondary combustion chamber, 6) dust separator, 7) heat exchanger, 8) outlet of the exhaust, 9) inlet of the cold water, 10) outlet of the hot water.

It is important to provide a sufficient distribution of air in the areas of the two combustion chambers. The boiler system is equipped with an air supply system, which uses a centrifugal fan and an air manifold in the form of pipes arranged in series, connected with the main pipe responsible for the transport of the air provided by the fan to each duct terminated by the nozzle. The air distributor of the examined boiler consist of seven pipes, welded on the front of the main duct, connected with the area of the primary combustion chamber. Additional two ducts are responsible for the feeding of air to the secondary combustion chamber. The combustion chambers are surrounded by a water jacket filled with water. More detailed information concerning the boiler can be found in [1].

To perform measurements of the temperature inside the combustion chambers, a PTTK thermocouple has been applied. The sensor that was to control the temperature during the experiment was situated on the rear wall of the boiler, just behind the inlet to the secondary combustion chamber. A MRU ECO 3000 exhaust analyzer has been applied during the experiments to control oxygen, carbon monoxide and carbon dioxide contents in the exhaust. The device is adapted to analyze all popular solid fuels, including biomass.

A PLC set is the heart of the control and measurement system. It includes a controller connected to a PC. The controller consist of modules which receive (from the sensors) and send (to the PC and other devices in the system) an analogue and digital signal.

\subsection{Description of the experiment}


Experimental tests of the combustion in case of the current state of the heating device have been carried out as the first stage of the study in order to analyze the dynamics of the process in respect of temperature changes at the inlet to the secondary combustion chamber, as well as the concentration of carbon monoxide in the exhaust. Before the measurement, warming of the device has been carried out to provide standard operation conditions during the experiment. Based on the procedure developed in previous works, it was decided to perform three series of experiments, which was deemed enough to confirm the repeatability of the process.

Straw in the form of cubes $(700 \times 500 \times 500 \mathrm{~mm})$ has been used. Estimated fuel weight for the individual test was $40 \mathrm{~kg}$, which is about $\sim 1 / 3^{\text {th }}$ of the nominal load (full primary combustion chamber). Moisture content in each straw cube has been measured by drying the sample of the biomass to a constant weight (using a dedicated stove). Water content was expressed as the percentage, based on the weight, of the sample before drying and weight of dry sample. The average value has been calculated based on results from three experimental series and amounted to $8.44 \%$.

Ignition has been initiated through a special orifice located at the rear bottom corner of the boiler side wall. After the ignition, the fan was run and its efficiency has been increased gradually (in $\sim 2$ minutes) to its maximum value $(250 \mathrm{dm} 3 / \mathrm{s})$. Each experiment has been carried out till the moment when the temperature in the considered measurement point was lower than $50^{\circ} \mathrm{C}(45$ minutes).

\subsection{Results of the experiment}

Based on the Arrhenius equation it can be said that, apart from the presence and type of oxidizer, temperature is the key factor determining the dynamics of the gasification process. Moreover, it has to be mentioned that carbon monoxide is the most important product of the gasification. Due to this fact, studies of relations between the concentration of carbon monoxide and the process temperature provide valuable information about the efficiency of energy conversion.

Figure 2 shows the dynamics of changes of the two aforementioned variables during the combustion process (averaged curves created based on data from three experiments). It is visible that the period of high $\mathrm{CO}$ concentration occurs before the phase of nominal combustion. It is a widespread phenomenon in the operation of batch boilers. Furthermore, the presented results are in agreement with the data presented in the previous paper, devoted to the analysis of the same heating unit [1].

This phenomenon is connected with the necessity of the stabilisation of the conditions in the combustion chamber, as well as with the highest intensity of the biomass devolatilisation during the first stage of combustion - directly after ignition. After the first $6 \sim 7$ minutes of the experiment, the concentration of $\mathrm{CO}$ decreases, although the high temperature persists due to the fact that most volatiles have been already released and the balance of the process is moved to the combustion of charcoal.

Due to the direct impact of the presence of an oxidizer and the concentration of the combustion process, it was necessary to calculate the excess air ratio. The value of this parameter in the period of the highest $\mathrm{CO}$ generation has been determined indirectly, based on equation 7

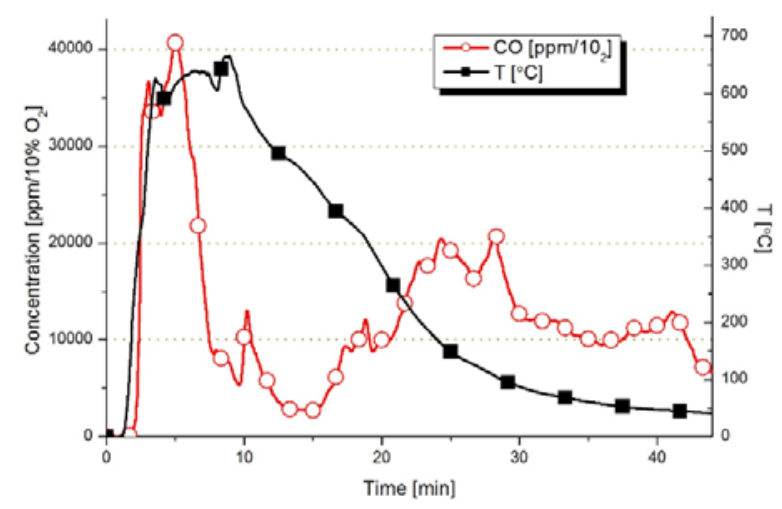

Figure 2. Concentration of $\mathrm{CO}$ behind the heat exchanger (outlet from the unit) and dynamics of temperature changes on the inlet to the secondary combustion chamber of the examined boiler.

$$
\lambda=\frac{\mathrm{CO}_{2 M A X}}{\mathrm{CO}_{2}},[-]
$$

Where:

$\mathrm{CO}_{2 \mathrm{MAX}}-$ maximum theoretical content of $\mathrm{CO}_{2}$ in the exhaust [\%]

$\mathrm{CO}_{2}-$ current concentration of $\mathrm{CO}_{2}$ in the exhaust [\%]

$\mathrm{CO}_{2 \max }$ has been calculated using the equation presented below:

$$
C O_{2 M A X}=\frac{21 C^{r}}{C^{r}+2,37\left(H^{r}-\frac{O^{r}-S^{r}}{8}\right)},[\%]
$$

Where:

$\mathrm{C}-$ carbon content in the biomass [\%]

$\mathrm{H}$ - hydrogen content in the biomass [\%]

$\mathrm{O}-$ oxygen content in the fuel [\%]

$\mathrm{S}-$ sulphur content in the biomass [\%]

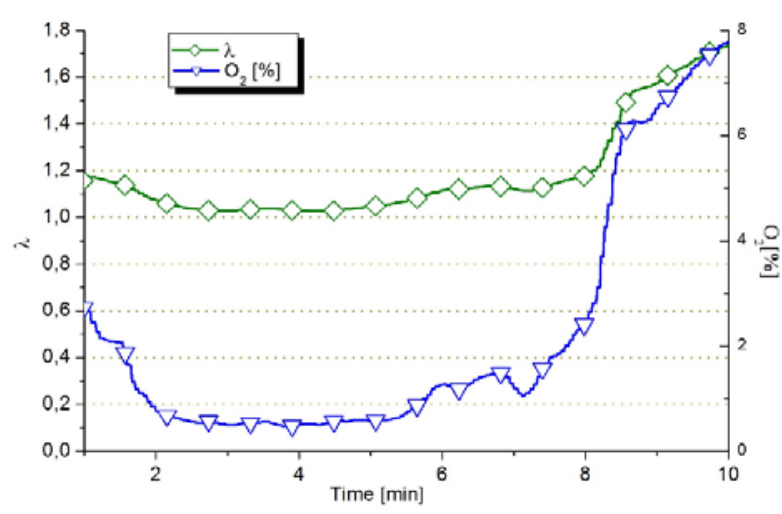

Figure 3. Excess air and concentration of oxygen in the exhaust in the first 10 minutes of the combustion process. 
The results of the calculation in comparison with the concentration of oxygen in the exhaust are presented in Figure 3, wherein the first minute is considered as the ignition stage and skipped. Despite reaching the full efficiency of the fan, excess air in the whole period of high CO emission is relatively low - between a little above 1 and 1.2. A low level of excess air is positive when it comes to stack losses. Moreover, it has to be taken into account that providing combustion air without preheating may in some cases lead to undesirable temperature reduction in the post-combustion region.

On the other hand, an excess air level that is too low can seriously impede the oxidation of the combustible gases in the secondary combustion chamber. It can result in problems with meeting the regulations concerning the range of pollutions emissions and in the increase of losses resulting from imperfect combustion.

It is important that in the considered period of the experiment (the first ten minutes), the combustion process occurs mainly in the secondary combustion chamber, because the primary chamber is still filled by the fuel and direct access to this part of the device is still closed.

Based on the aforementioned results of the experimental tests it was concluded that it is required to perform an evaluation of the impact of the excess air in the secondary combustion chamber on the key parameters of the operation, which determine the efficiency of the heating unit.

In case of technical limitations (such as parameters of the fan installed on the experimental stand), CFD provides the possibility to carry out simplified variant analysis of conditions of $\mathrm{CO}$ post-combustion depending on the excess air. The results of numerical modelling described in the paper were useful in deciding on the process of increasing the efficiency of the boiler.

\section{Numerical studies of the post- combustion in the secondary combustion chamber of a $180 \mathrm{~kW}$ biomass boiler}

\subsection{Development of the numerical model for the homogenous combustion}

A numerical CFD model has been developed to analyse the phenomena occurring at the beginning of the combustion in the area of the secondary combustion chamber, especially in respect of the impact of the excess air on the selected operational parameters. A fluid dynamics model applied at the previous stage of the research [1] has been implemented. The kinetics of the chemical reactions were based on "Finite Rate Eddy Dissipation". Furthermore, the previous simple combustion model was developed based on the set of equations describing the chemical reactions [2]:

$$
\begin{gathered}
\mathrm{CO}+\frac{1}{2} \mathrm{O}_{2} \stackrel{E_{a 1}, A_{1}}{\longrightarrow} \mathrm{CO}_{2} \\
\mathrm{CO}_{2} \stackrel{E_{a 2}, A_{2}}{\longrightarrow} \mathrm{CO}+\frac{1}{2} \mathrm{O}_{2}
\end{gathered}
$$

$$
\begin{gathered}
\mathrm{H}_{2}+\frac{1}{2} \mathrm{O}_{2} \stackrel{E_{a 3}, A_{3}}{\longrightarrow} \mathrm{H}_{2} \mathrm{O} \\
\mathrm{CH}_{4}+2 \mathrm{O}_{2} \stackrel{E_{a 4}, A_{4}}{\longrightarrow} 2 \mathrm{H}_{2} \mathrm{O}+\mathrm{CO}_{2} \\
\mathrm{NH}_{3}+\mathrm{O}_{2} \stackrel{E_{a 5}, A_{5}}{\longrightarrow} \mathrm{NO}+\mathrm{H}_{2} \mathrm{O}+\frac{1}{2} \mathrm{H}_{2} \\
\mathrm{NH}_{3}+\mathrm{NO} \stackrel{E_{a 6}, A_{6}}{\longrightarrow} \mathrm{N}_{2}+\mathrm{H}_{2} \mathrm{O}+\frac{1}{2} \mathrm{O}_{2} \\
\mathrm{HCN}+\mathrm{O}_{2} \stackrel{E_{a 7}, A_{7}}{\longrightarrow} \mathrm{NO}+\mathrm{CO}+\frac{1}{2} \mathrm{H}_{2} \\
\mathrm{HCN}+\mathrm{NO} \stackrel{E_{a 8}, A_{8}}{\longrightarrow} \mathrm{N}_{2}+\mathrm{CO}+\frac{1}{2} \mathrm{H}_{2}
\end{gathered}
$$

The applied values of the activation energy as well as the pre- exponential factors corresponding to the respective chemical reactions are collected in Table 1.

Table 1. Activation energies $\left(E_{a}\right)$ and pre-exponential factors (A) applied in reactions described by equations 3-10.

\begin{tabular}{|c|c|c|c|c|}
\hline No. & $\mathbf{1}$ & $\mathbf{2}$ & $\mathbf{3}$ & $\mathbf{4}$ \\
\hline $\left.\begin{array}{c}\mathrm{E}_{\mathrm{a}} \\
{\left[\frac{\mathrm{Jg} \cdot \mathrm{mol}}{}\right.}\end{array}\right]$ & $1.7 \cdot 10^{8}$ & $1,7 \cdot 10^{8}$ & $3.1 \cdot 10^{7}$ & $1.27 \cdot 10^{8}$ \\
\hline $\mathrm{A}$ & $2.239 \cdot 10^{12}$ & $5 \cdot 10^{8}$ & $9.87 \cdot 10^{8}$ & $1.0729 \cdot 10^{10}$ \\
\hline No. & $\mathbf{5}$ & $\mathbf{6}$ & $\mathbf{7}$ & $\mathbf{8}$ \\
\hline $\begin{array}{c}\mathrm{E}_{\mathrm{a}} \\
{\left[\frac{\mathrm{Jg} \cdot \mathrm{kol}}{}\right]}\end{array}$ & $6.65 \cdot 10^{7}$ & $6.65 \cdot 10^{7}$ & $2.8 \cdot 10^{8}$ & $2.5 \cdot 10^{8}$ \\
\hline $\mathrm{A}$ & $12.1 \cdot 10^{3}$ & $8.73 \cdot 10^{14}$ & $1 \cdot 10^{10}$ & $3 \cdot 10^{12}$ \\
\hline
\end{tabular}

Spatial geometry has been performed in Autodesk Inventor 2015 software. Subsequently, the geometry has been exported to the ANSYS Workbench, first to the ANSYS DesignModeler module, which allows to perform additional edition of the geometric model. Then a discretisation of the continuous domain has been carried out using ANSYS Meshing. The process of mesh generation has been performed in a way that guarantees the predominance of hexagonal grid elements. The discretisation has been carried out using the "Multizone", the "Hex dominant" and the automatic method. The total number of grid elements was $1.5 \cdot 10^{6}$. $\mathrm{K}$-epsilon "realizable" model of turbulence has been applied.

Thermal properties of the wall materials have been taken into account by a function which is based on the definition of the material (steel), the wall thickness $(8$ $\mathrm{mm}$ ) and the temperature of the operating medium on the other side of the wall. A "Discrete Ordinate" model of radiation, which is based on angular discretisation, has been applied to take into account the spectral properties (absorption coefficient) of molecules consisting of three atoms.

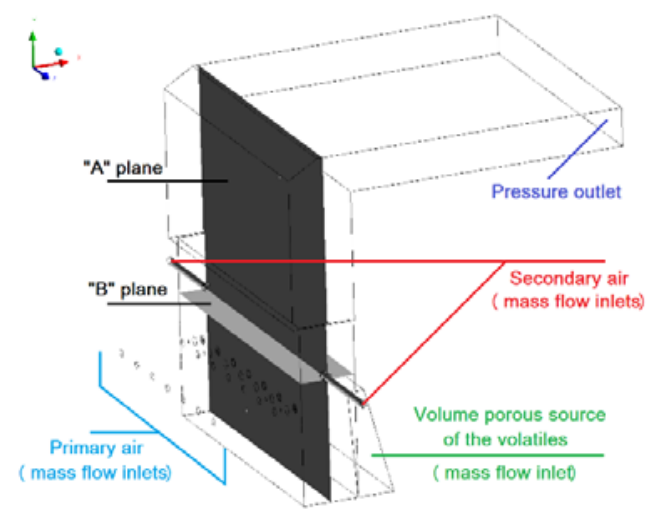


Figure 4. Sketch of the computational domain considered in the numerical analysis with a simplified description of the basic boundary conditions and the position of the cross sectional planes ("A" and "B") used in the analysis of the results.

Figure 4 is a sketch of the computational domain and simplified description of boundary conditions. The whole domain has been defined as a continuous fluid, except for the inlet region, which has been defined as a porous body and set as a volume source of the volatiles. This part of the domain represents piece of the straw bale. The gas at the inlet has been defined as a mixture of compounds which are reagents in the previously mentioned reactions.

Nine air inlets have been defined - seven on the rear wall (R1-R7) of the secondary combustion chamber (primary air) and two (D1, D2) on the side walls (secondary air). The air mass flow for each duct has been set based on the results of experimental tests and numerical analysis of the air manifold carried out by the author, which are described in [21].

To include the impact of the chimney draft on the process, negative pressure on the outlet from the computational domain $(-20 \mathrm{~Pa})$ has been set. Ten variants of the excess air $(1.25-3,5)$ have been analyzed to determine the basic relations between this coefficient and the selected operational parameters of the heating device.

A steady state analysis has been carried out. The residues for the governing equations have been set on the level of $10^{-5}$. A "First order upwind" advection scheme has been applied in the first approach. Then it has been changed to "Second order upwind" in case of the momentum and energy equations in the final computation.

\subsection{Results of the numerical simulation of the homogenous combustion}

Results obtained in the process of computations for the first case of excess air (lambda $=1.1$ ) are fully comparable with the experimental data when it comes to CO concentration (Fig. 5). Due to the fact that the real combustion in the considered stage (stabilization of the combustion just after ignition, in the first few minutes) is strongly unstable, it is impossible to reproduce this process faithfully. The agreement of the numerical and experimental data, however, is fully satisfying.

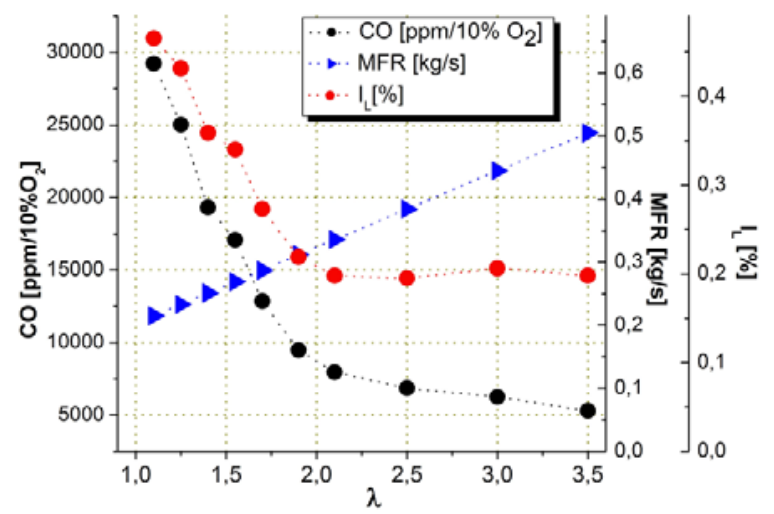

Figure 5. CO concentration, mass flow rate of the exhaust (MFR) as well as the loss caused by imperfect combustion as a function of the excess air.

The results of the variant analysis show that it is possible to control the efficiency of the combustion by the modulation of air streams. From the second variant on, the concentration of $\mathrm{CO}$ in the exhaust increases. The increase of excess air results in a better access to the oxidizer as well as a higher mixing rate, which is a key issue in case of $\mathrm{CO}$ combustion. After the critical point $(\lambda=1.9)$, the dynamics of decrease of the CO content become significantly lower. It has to be underlined that the concentration of $\mathrm{CO}$ in each chart in the paper has been recalculated to $10 \%$ of the air concentration in the exhaust.

Apart from CO concentration, Figure 5 presents also the changes of relative amount of energy connected to the losses resulting from imperfect combustion, which is the result of the presence of combustible gases in the exhaust. The value of this parameter behaves analogously to the concentration of $\mathrm{CO}$, due to the fact that this compound has been taken into account as the most significant combustible component of the mixture in the secondary combustion chamber.

The loss resulting from imperfect combustion has been calculated based on the equation below:

$$
I_{L}=\frac{V_{S S} \cdot Q_{C O} \cdot C O}{Q_{w}},[\%]
$$

Where:

$\mathrm{V}_{\mathrm{ss}}$ - exhaust volume flow rate $\left[\frac{\mathrm{m}^{3}}{\mathrm{~s}}\right]$

$\mathrm{Q}_{\mathrm{CO}}-$ calorific value of the $\mathrm{CO}\left[\frac{\mathrm{MJ}}{\mathrm{kg}}\right]$

$\mathrm{CO}-\mathrm{CO}$ content in the exhaust [\%]

$\mathrm{Q}_{\mathrm{w}}$ - calorific value of the biomass $\left[\frac{\mathrm{MJ}}{\mathrm{kg}}\right]$

The calorific value of the biomass fuel has been calculated using the equation below:

$$
Q_{w}=339 \cdot C+1214,2\left(H_{2}-\frac{o}{8}\right)+104,7 S-25,1 W,\left[\frac{M J}{k g}\right](18
$$

Where:

$\mathrm{C}, \mathrm{H}_{2}, \mathrm{O}, \mathrm{S}$ - content of the compound in the biomass [\%]

$\mathrm{W}-$ content of moisture in the biomass [\%]

The specifics of the changes of the imperfect combustion loss can be explained based on the results presented in Figure 6, which displays the distribution of the $\mathrm{CO} 2$ mass fraction on the plane constituting the "B" cross section (see Fig. 4) of the computational domain.

In the reference case $($ lambda $=1.1)$, the area of the combustion, which is characterised by a relatively high concentration of $\mathrm{CO} 2$, is located in the centre of the chamber. Due to a relatively low mass air flow rate, the velocity of the mixture in the aforementioned section is low and the reactions are occurring between the secondary air nozzles.

Along with the increase of the excess air, the combustion area is moving to the corners of the combustion chamber. In case of $\lambda=1.9$ the intensity of 
the process is the greatest. The sections characterised by the highest $\mathrm{CO}_{2}$ concentration are the widest, despite a much higher oxygen content than in the example "a". In case of excess air amounting to 3.5, the conditions in the chamber undergo deterioration.

The increase of a relatively cold air stream results in the cooling down of the combustion chamber. It has to be said that the concentration of $\mathrm{CO}_{2}$ is directly tied to the temperature at the outlet from the computational domain, which can be noted based on Figure 6 and 7 .

In case of the three first variants, the temperature decreases slightly due to the increasing amount of air in the combustion area. A reversal is noted when the excess air reaches 1.55. Between lambda $=1.55$ and 1.9 the range of the best conditions is observed. It has to be noted that the excess air values which cause the highest temperatures are tied to the most dynamic reduction of CO.

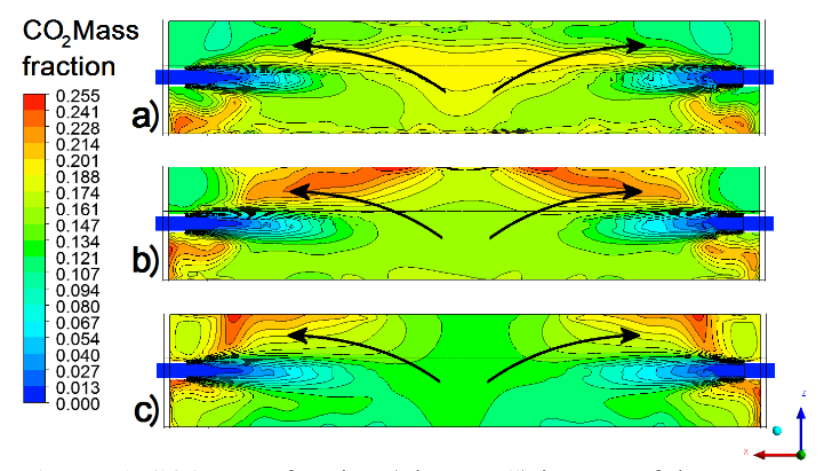

Figure 6. $\mathrm{CO} 2$ mass fraction (plane "B") in case of the excess air amounting to 1.1 (a), 1.9 (b) and 3.5 (c). The black arrows show the direction of the "movement" of the region of high combustion intensity.

Moreover, relatively low temperatures calculated for excess air greater than 2.1 explain the stabilisation of the level of CO concentration.

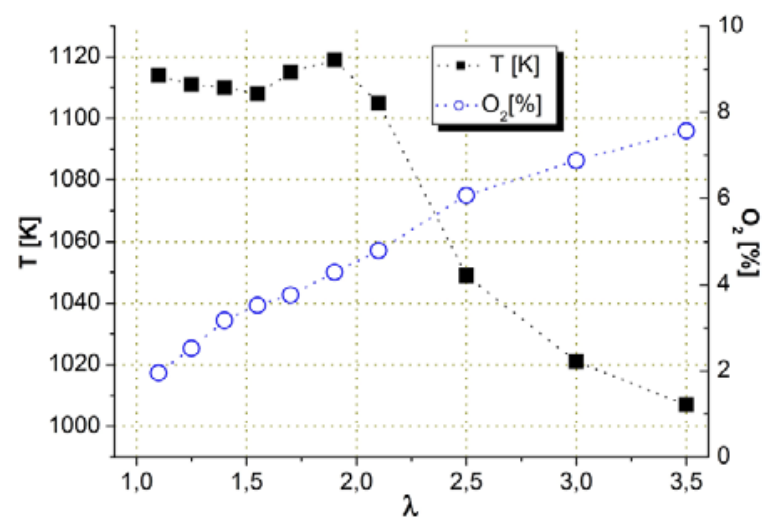

Figure 7. Temperature of the exhaust leaving the computational domain and concentration of oxygen as a function of the excess air.

The increase of the velocity of the air streams results in a significant change of the temperature distribution in the secondary combustion chamber. Figure 8 shows the change of location of the regions of high temperature, which corresponds to the increase of the excess air.

Two extreme cases (1.1 and 3.5) as well as the optimal one (1.9) have been presented. Due to the more efficient penetration of the domain by the cold air, the process of combustion in the centre of the chamber is disturbed. The areas of high temperature are moving to the side walls of the combustion chamber.

Comparison of Figure $6 \mathrm{c}$ and $9 \mathrm{c}$ allows to note that in case of the considered plane, the regions which are characterised by the highest kinetic energy of turbulence are also the coldest areas. Due to this fact, efficient postcombustion of carbon monoxide is very difficult. Based on the discussed results it is possible to conclude that in case of the studied process the decisive factor is temperature.

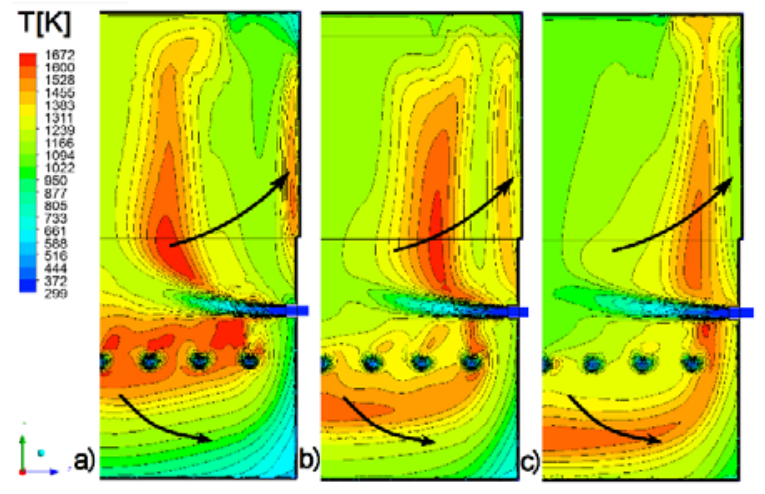

Figure 8. Distribution of temperature (" $A$ " plane) in case of the excess air amounting to 1.1 (a), 1.9 (b) and 3.5 (c). The black arrows show the direction of "movement" of the region of high combustion intensity.



Figure 9. Kinetic energy of turbulence ("B" plane) in case of the excess air amounting to 1.1 (a), 1.9 (b) and 3.5 (c).

The level of turbulences has a positive impact on the combustion efficiency but it is necessary to avoid excessive temperature reduction. Due to this fact, it is recommended to provide efficient mixing by appropriate design of the nozzles instead increasing of the inlet air velocity.

However, the higher the temperature of the gases leaving the combustion chamber, the greater is the amount of energy that may be lost due to stack loss. Based on the results of the numerical simulation it was possible to estimate the amount of energy which is carried out of the secondary combustion chamber by the exhaust stream (Fig. 9). It was calculated using the equation below.

$$
E_{L}=\sigma \cdot \frac{\left(T_{1}-T_{2}\right)+0,59 \cdot C O}{\mathrm{CO}_{2}+\mathrm{CO}},[\%]
$$

Where: 
$\sigma$ - Siegert constant (calculated based on the content of moisture in the fuel and the average $\mathrm{CO}_{2}$ emissions during the combustion)

$\mathrm{T}_{1}$ - exhaust temperature $[\mathrm{K}]$

$\mathrm{T}_{2}$ - ambient temperature $[\mathrm{K}]$

$\mathrm{CO}, \mathrm{CO}_{2}-$ content of the compound in the exhaust [\%]

As it can be seen in Figure 10, the exhaust loss increases with the increase of the excess air and in last case it reaches $\sim 50 \%$. Two factors determine the permanent trend of the exhaust loss curve. Up to $\lambda=1.9$ the increase of the loss is the result of the increasing difference between gas temperature and ambient temperature. Based on equation (19) it can be noted that in case of greater values of the excess air, $\mathrm{CO}_{2}$ concentration is the key factor determining the value of energy loss.

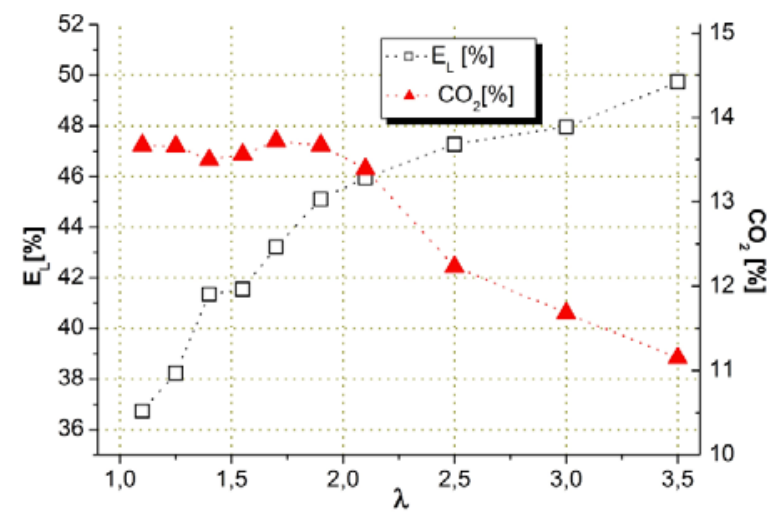

Figure 10. Relative amount of the energy carried by the exhaust and concentration of $\mathrm{CO}_{2}$ in the exhaust as a function of the excess air.

The concentration of $\mathrm{CO}_{2}$ calculated at the outlet of the secondary combustion chamber decreases along with the post-combustion of $\mathrm{CO}$ and consequently the production of $\mathrm{CO}_{2}$ increases with the increase of the excess air. It is connected to a dynamic increase of $\mathrm{O}_{2}$ concentration in the region of the highest intensity of the chemical reactions.

\subsection{Development of the numerical model for the heterogeneous combustion}

The second step of the research described in this paper was inclusion of the transport of the solid phase in the previous numerical model of the homogenous combustion. Moreover, a simplified model of particle matter combustion has been developed.

A "Discrete Phase Model" (DPM) available in the ANSYS Fluent Solver has been applied to describe the transport of the particles lifted by the gases in the secondary combustion chamber from the fuel bed. The first approach assumed the definition of twenty point sources (so called "injectors") of discrete phase particles. The injectors have been located in three parallel rows characterized by different distances from the floor of the combustion chamber. Sources were situated in the area of the porous domain, which represents a piece of the straw bale.
The discrete phase was set as interacting with the continuous phase. The physical properties of the individual particles have been defined based on the values characteristic for the straw. A "kinetics/diffiusonlimited" model of combustion has been implemented. Due to the simplified approach, a uniform diameter of the particle amounting to lum has been assumed.

The previous set of reactions has been expanded. Based on tools available in ANSYS Fluent as well as the description of the elementary reactions, an additional equation describing the combustion of the volatiles released from the solid particles has been developed:

$$
\begin{gathered}
\text { volatiles }+0.622 \mathrm{O}_{2} \stackrel{E_{a 9}, A_{9}}{\longrightarrow} \\
0.924 \mathrm{CO}+1.316 \mathrm{H}_{2} \mathrm{O}+0.0085 \mathrm{~N}_{2}+0.001 \mathrm{SO}_{2}
\end{gathered}
$$

Where:

$\mathrm{E}_{\mathrm{a} 9}=2.027 \cdot 10^{9}\left[\frac{\mathrm{J}}{\mathrm{kg} \cdot \mathrm{mol}}\right]$
$\mathrm{A}_{9}=2.119 \cdot 10^{11}$

It has to be noted that the thermochemical conversion of the solid particles has been considered as wet combustion. Due to this fact, the liquid fraction (0.04169) has been defined in case of each injector. However, some mechanisms, such as turbulent dispersion, have been skipped at the current stage of the model development.

Two cases of discrete phase mass flow rate have been considered. Mass flow rates were calculated based on the assumption that in the first case, the chemical energy of the total discrete phase stream constitutes $1 \%$ of the chemical energy of the gasification products $\left(\mathrm{E}_{\mathrm{DPM}}=\right.$ $1 \%)$, while in the second case it is $10 \%\left(\mathrm{E}_{\mathrm{DPM}}=10 \%\right)$.

The chemical energy of the discrete phase particles has been calculated based on equation 18. The chemical energy of the gasification products $\left(\mathrm{Q}_{\mathrm{g}}\right)$ has been determined using the following equation:

$$
Q_{g}=\dot{\mathrm{m}}_{f} \cdot\left(\sum_{i=1}^{n} x_{i} \cdot Q_{i}\right)
$$

Where:

$\dot{\mathrm{m}}_{\mathrm{f}}$ - mass flow rate of the gasification products $\left[\frac{\mathrm{kg}}{\mathrm{s}}\right]$

$\mathrm{x}_{\mathrm{i}}$ - mass fraction of the combustible component

$\mathrm{Q}_{\mathrm{i}}$ - calorific value of the combustible component $\left[\frac{\mathrm{MJ}}{\mathrm{kg} \cdot \mathrm{K}}\right]$

The mass flow rate of the discrete phase, which corresponds to $1 \%$ and $10 \%$ of the gas mixture energy, has been calculated using appropriate proportions and it amounted to $2,86 \cdot 10^{-4} \mathrm{~kg} / \mathrm{s}$ and $2,86 \cdot 10^{-3} \mathrm{~kg} / \mathrm{s}$, respectively. Based on the results of studies of homogeneous combustion it was decided that the reference case with lambda $=1.1$ as well as three promising cases of the excess air: 1.55, 1.7 and 1.9 should be considered in the further simulations.

\subsection{Results of the numerical simulation of the heterogeneous combustion}

As the first step of the investigation of the impact of the presence of the discrete phase on the combustion in the secondary combustion chamber, the $\mathrm{CO}_{2}$ concentration 
has been analysed. Figures 11 and 12 show the distribution of the component depending on the percentage of the chemical energy of the discrete phase (EDPM) and excess air.

Based on comparison with the areas of high temperature in case of homogenous combustion which were presented in Figure 8 it can be noted that the gasification of the particulate matter occurs in a higher section of the chamber. The effect of the expansion of the areas of high concentration of $\mathrm{CO}_{2}$ with the increase of the mass flow rate of the discrete phase is directly connected to the combustion of carbon monoxide released from the solid particles.

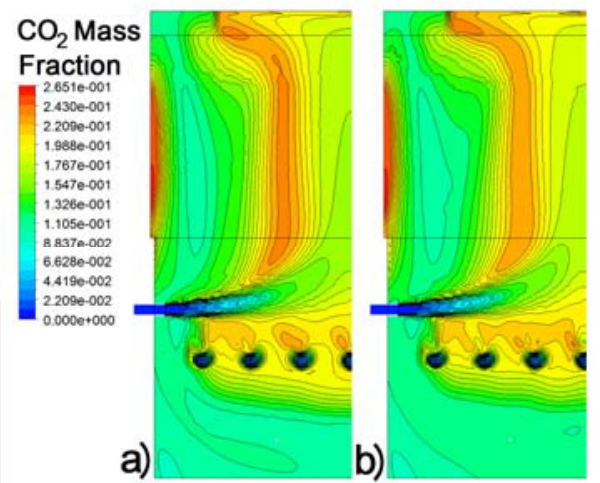

Figure 11. Distribution of $\mathrm{CO}_{2}$ (" $\mathrm{A}$ " plane) in the secondary combustion chamber: a) $\lambda=1.1, \mathrm{E}_{\mathrm{DPM}}=1 \%$, b) $\lambda=1.1, \mathrm{E}_{\mathrm{DPM}}$ $=10 \%$.

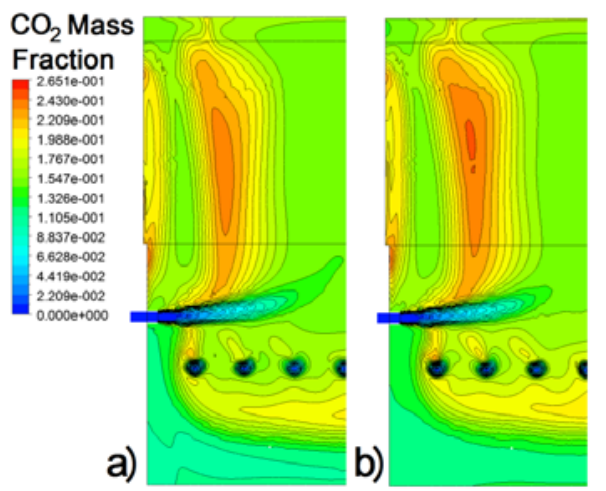

Figure 12. Distribution of $\mathrm{CO}_{2}$ ("A" plane) in the secondary combustion chamber: a) $\lambda=1.9, \mathrm{E}_{\mathrm{DPM}}=1 \%$, b) $\lambda=1.9, \mathrm{E}_{\mathrm{DPM}}$ $=10 \%$.

The inclusion of the gasification process in the area of the secondary combustion chamber requires the consumption of a certain amount of energy, so it has to influence the heat balance of the reaction. However, the exhaust temperature calculated for the two considered variants of the discrete phase content (Figure 13) is fully comparable with the results obtained in the analysis of the homogenous combustion. It can be concluded that the thermal effect of the gasification is compensated by the effect of combustion of the released CO.

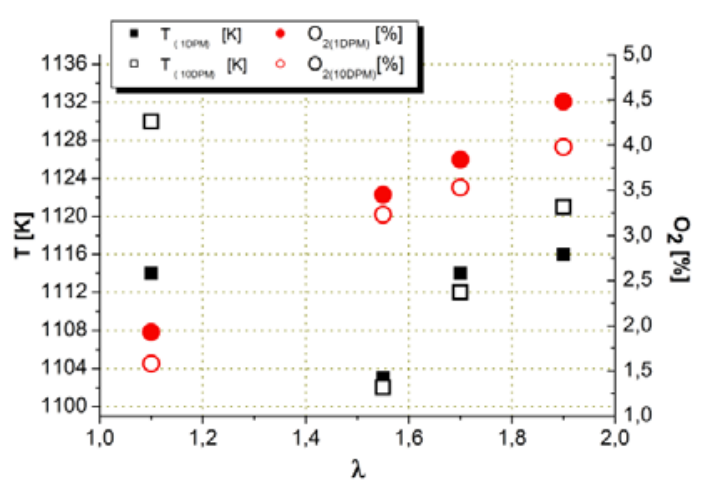

Figure 13. Temperature of the exhaust leaving the computational domain and concentration of oxygen in case of $\mathrm{E}_{\mathrm{DPM}}=1 \%$ and $\mathrm{E}_{\mathrm{DPM}}=10 \%$ as a function of the excess air.

The exhaust temperature was again directly related to the excess air. In the whole range of the analysed values of the excess air, the mole fraction of oxygen is lower for variants including higher content of the discrete phase in the chamber. The combustion of the released $\mathrm{CO}$ becomes effective from the point where the excess air amounts to 1.55 , which results in an increased temperature at the outlet of the computational domain.

Figure 14 presents the impact of the particulate matter content and excess air value on the phenomena occurring at the height of the secondary air nozzles. The effect of the expansion of the intensive combustion regions is visible here as well. However, it is significant in case of lambda $=1.1$ due to the influence of the relatively cold air on the temperature at the centre of the considered section of the chamber. In each variant, the gas phase reactions are critical, which results in the influence of the excess air on the process analogous to the one taking place in case of homogeneous combustion.

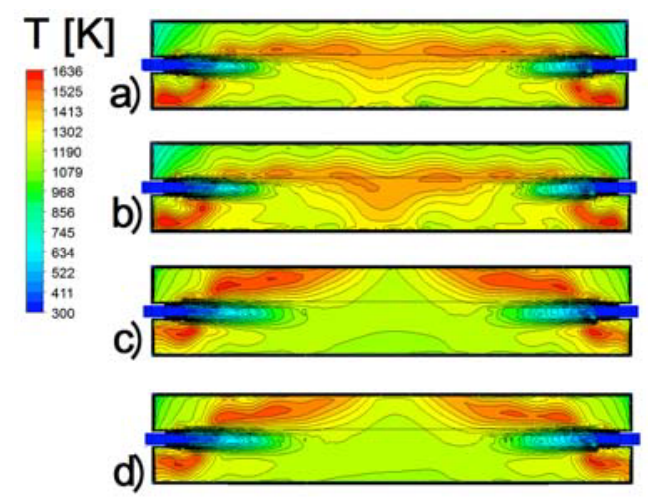

Figure 14. Distribution of temperature ("B" plane): a) $\lambda=1.1$, $\mathrm{E}_{\mathrm{DPM}}=1 \%$, b) $\lambda=1.1, \mathrm{E}_{\mathrm{DPM}}=10 \%$, c) $\lambda=1.9, \mathrm{E}_{\mathrm{DPM}}=1 \%$, d) $\lambda=1.9, \mathrm{E}_{\mathrm{DPM}}=10 \%$.

The values of exhaust loss (Figure 15) determined both for $\mathrm{E}_{\mathrm{DPM}}=1 \%$ and $\mathrm{E}_{\mathrm{DPM}}=10 \%$ are slightly lower than for the homogeneous combustion, except for lambda $=1.1$. The values calculated for the incomplete combustion loss in case of $\mathrm{E}_{\mathrm{DPM}}=10 \%$ are the highest from among all the cases considered in the described research. It is the result of the release of a relatively big 
amount of $\mathrm{CO}$ in the higher sections of the combustion chamber.

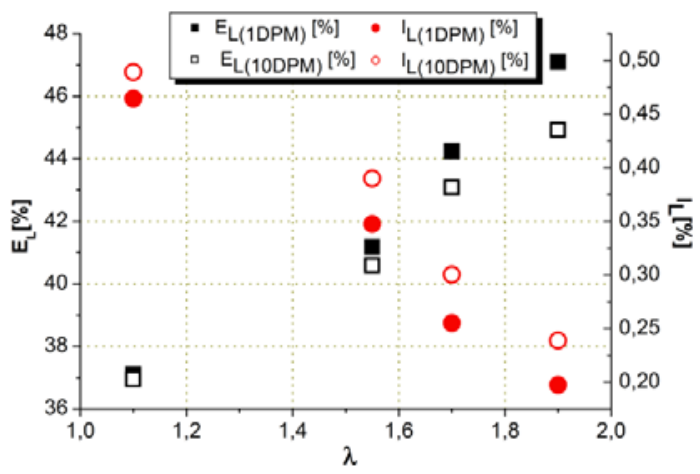

Figure 15. Relative amount of the energy carried by the exhaust $\left(\mathrm{E}_{\mathrm{L}}\right)$ and loss resulting from imperfect combustion $\left(\mathrm{I}_{\mathrm{L}}\right)$ as a function of the excess air in case of $\mathrm{E}_{\mathrm{DPM}}=1 \%$ and $\mathrm{E}_{\mathrm{DPM}}=$ $10 \%$.

Due to the location of the secondary air nozzles on the side walls of the chamber, during the flow to the outlet solid particles are pushed from the centre of the domain to the walls. This is one of the significant reasons for changes of the range of the combustion region in these parts of the computational domain.

However, the movement of the discrete phase elements is relatively undisturbed outside the region of the contact of streams blown from the secondary air nozzles. Due to this fact, it is recommended to implement modified nozzles which would allow for the prolongation of the path of particles to the outlet by means of intensifying the turbulences [1].

Moreover, it has to be taken into account that the implementation of the distribution of the diameter of the particulate matter influences the flow parameters of the particles and consequently results in specific tracks of the discrete phase elements. However, the research presented in this paper was focused primarily on the impact of the presence of discrete phase on the changes of conditions in the secondary combustion section of the boiler.

\section{Summary and conclusions}

Based on the numerical modelling which has been carried out using the ANSYS Fluent solver it was discovered that an increase of the excess air in case of combustion occurring in the secondary chamber of the straw-fired batch boiler leads to a significant reduction of $\mathrm{CO}$ emissions. However, an increase of the exhaust stream resulting from the higher excess air causes higher levels of losses. The results of the conducted computations allow to conclude that in the examined boiler type it is recommended to apply excess air on the level between 1.55 and 1.9, which is in general agreement with the recommendations of the producer $(\lambda$ $=1.25-1.75)$. The implementation of a discrete phase model results in changes in temperature distribution as well as different local concentrations of important products of chemical reactions. However, in case of a relatively low amount of particulate matter applied in the model, no significant changes in heat balance are observed. The inclusion of a discrete phase model in the study of the operation of biomass-fired batch boilers is necessary when studying issues related to the reduction of the particulate matter emissions. Furthermore, the gasification of the solid particles lifted up from the fuel bed may be considered an important mechanism of $\mathrm{CO}$ production. Due to the combustion dynamics in case of batch heating units it is recommended to apply a dynamic control of the air feed, based on measurements of the exhaust temperature, excess air and a selected compounds such as $\mathrm{CO}$ or $\mathrm{O}_{2}$.

This study was carried out under the "BioORC: Construction of cogeneration system with small to medium size biomass boilers" project.

\section{References}

1. M. Szubel, EFM 2015: Proceedings of the International Conference, Prague, Czech Republic

2. M. Miltner, A. Makaruk, M. Harasek, A. Friedl, Cl. Tech. and Env. Pol., 5 (2008)

3. B. Sørensen, Renewable Energy. Its physics, engineering, environmental impacts, economics \& planning (Academic Press, Boston, 2000)

4. L. Rosendahl, Biomass combustion science, technology and engineering (Woodhead Publishing, Oxford 2013)

5. T. B. Johansson, H. Kelly, A. K. N. Reddy, R. H. Williams, Renewable Energy Sources for Fuels and Electricity (Island Press, Washington 1993)

6. S. van Loo, J. Coppejan, The handbook of biomass combustion and co-firing (EARTHSCAN, London 2008)

7. P. Basu, Biomass gasification and pyrolysis practical design (Academic Press, Boston, 2010)

8. S. R. Turns, An introduction to combustion. Concepts and applications, (McGraw-Hill, Boston 2000)

9. I. Glassman, Combustion (Academic Press, Orlando 1987)

10. R. A. Yetter, F. L. Dryer, H. Rabitz, $A$ comprehensive reaction mechanism for carbon monoxide/hydrogen/oxygen kinetics, Comb. Sc. and Tech., 79 (1981)

11. D. J. Hautman, F. L. Dryer, K. P. Schug, I. A. Glassman, A multiple step overall kinetic mechanism for the oxidation of hydrocarbons, Comb. Sc. And Tech. 25 (1981)

12. C. K. Westbrook, F. L. Dryer, Simplified reaction mechanisms for the oxidation of hydrocarbon fuels in flames, Comb. Sc. And Tech., 27 (1981)

13. H. K. Versteeg, W. Malalasekera, An Introduction to Computational Fluid Dynamics. The Finite Volume Method (Pearson Education Limited, Harlow, 2007)

14. L. Chaoqun, T. Jiyuan, Y. Guan-Heng, Computational Fluid Dynamics. A Practical Approach (Butterworth-Heinemann, Oxford 2013) 
15. A. Bianchini, F. Cento, L. Golfera, M. Pellegrini, C. Saccani, Performance analysis of different scrubber systems for removal of particulate emission from a small size biomass boiler, Biom. and Bioen. 92 (2016)

16. Q. Xue, T. J. Heindel, R. O. Fox, A CFD model for biomass fast pyrolysis in fluidized-bed reactors, Chem. Eng. Sc., 66 (2011)

17. J. Blondeau, H. Jeanmart, Biomass pyrolysis in pulverized-fuel boilers: Derivation of apparent kinetic parameters for inclusion in CFD codes, Proc. of Com. Inst., 33 (2011)

18. R. Baczyński, R. Weber, A. Szlęk, Innovative design solution for small-scale domestic boilers: Combustion improvements using a CFD-based mathematical model, Journ. of En. Inst., 88 (2015)

19. J. Chaney, H. Liu, L. Li, An overview of CFD modelling of small-scale fixed-bed biomass pellet boilers with preliminary results from simplified approach, En. Conv. and Man., 63 (2012)

20. J. Collazo, J. Porteiro, J.L. Miguez, E. Granada, M.A. Gómez, Numerical Simulation of a small-scale biomass boiler, En. Conv. and Man., 64 (2012)

21. M. Szubel, T. Siwek, Optimization of the operation of energy devices on the example of an air distribution system inside the biomass boiler, Tech. Trans. 19 (2014) 